\title{
Correction to: The effect of acute vs chronic magnesium supplementation on exercise and recovery on resistance exercise, blood pressure and total peripheral resistance on normotensive adults
}

\section{S. Kass ${ }^{*}$ and F. Poeira}

\section{Correction}

The original article [1] contains an error whereby the datum value of '17.7\%' in both the Abstract and the first line of the Bench press sub-section of the Results section is incorrect. The value should instead be '7.7\%'.

Received: 26 June 2018 Accepted: 11 July 2018

Published online: 25 July 2018

\section{Reference}

1. Kass $L S$, Poeira F. The effect of acute vs chronic magnesium supplementation on exercise and recovery on resistance exercise, blood pressure and total peripheral resistance on normotensive adults. J Int Soc Sports Nutr. 2015;12:19. https://doi.org/10.1186/s12970-015-0081-z. 